\title{
Implementing a Dictionary Culture in South Africa: An Attempt at a General Framework for the African Languages*
}

\author{
Juliane Klein, Institut für Afrikanistik, University of Leipzig, Leipzig, \\ Germany (klein.juliane@freenet.de)
}

\begin{abstract}
The development of a dictionary culture consists of three main phases: (a) the information phase, (b) the learning phase and (c) the consolidation phase. The first step towards a new dictionary culture is to inform mother-tongue speakers of available dictionaries and their benefits for individual speakers. This information should mainly be distributed through dictionary awareness campaigns conducted in the relevant African languages and by influential mother-tongue speakers. The main difficulty of the learning phase consists in the teaching of different groups, for example lexicographers, teachers and students, as well as adults who want to consult a dictionary effectively. Although a basic knowledge of lexicography is useful for teachers, a natural association with dictionaries as well as an intimate knowledge of dictionaries is more important. An intimate knowledge of dictionaries includes, among others: the different dictionary types, the contents of dictionaries and the know-how to find the sought-for word. The last phase is the consolidation phase in which the association with dictionaries will change from an uncommon to a normal activity.
\end{abstract}

Keywords: DICTIONARY CULTURE, INFORMATION, NATIONAL LEXICOGRAPHIC UNITS, DICTIONARIES, AFRICAN LANGUAGES, DICTIONARY AWARENESS CAMPAIGNS, EMPOWERMENT, TEACHING PHASE, USER, MEDIA, CONSOLIDATION PHASE, INCLUSIVE MODEL

Zusammenfassung: Implementierung einer Wörterbuchkultur in Südafrika: Ein Versuch eines allgemeinen Modells für die afrikanischen Sprachen. Die Entwicklung einer Wörterbuchkultur besteht aus drei Hauptphasen: (a) die Informationsphase, (b) die Lernphase und (c) die Festigungsphase. Der erste Schritt zu einer neuen Wörterbuchkultur ist es, Muttersprachler über erhältliche Wörterbücher und ihre Vorteile für den einzelnen Sprecher zu informieren. Diese Informationen sollen hauptsächlich durch Initiativen zum Gebrauch von Wörterbüchern, die in den entsprechenden afrikanischen Sprachen ausgeführt werden müssen, und einflussreiche Muttersprachler verbreitet werden. Die Hauptschwierigkeit der Lernphase besteht

* An earlier version of this article was presented as a paper at the Eleventh International Conference of the African Association for Lexicography organised by the Tshivenda National Lexicographic Unit, University of Venda for Science and Technology, Thohoyandou, Republic of South Africa, 5-7 July 2006. 
darin, daß unterschiedlichen Gruppen zu unterrichten sind, z.B. Lexikographen, Lehrer, Schüler, sowie Erwachsene die ein Wörterbuch erfolgreich benutzen wollen. Obwohl ein grundlegendes Wissen über Lexikographie für Lehrer nützlich ist, sind der selbstverständliche Umgang mit Wörterbüchern sowie ein Grundwissen über Wörterbücher wichtiger. Zu dem Grundwissen über Wörterbücher zählen unter anderem: Die verschieden Wörterbuchtypen, Inhalte der Wörterbücher und das Wissen das gesuchte Wort zu finden. Die letzte Phase ist die Stabilisierungsphase in welcher der Umgang mit Wörterbüchern von einer seltenen zu einer alltäglichen Aktivität werden soll.

Stichwörter: WÖRTERBUCHKULTUR, INFORMATION, NATIONAL LEXICOGRAPHIC UNITS, WÖRTERBÜCHER, AFRIKANISCHE SPRACHEN, INITIATIVEN ZUM GEBRAUCH VON WÖRTERBÜCHERN, EMPOWERMENT, LERNPHASE, BENUTZER, MEDIEN, STABILISIERUNGSPHASE, INKLUSIVES MODELL

\section{Introduction}

In South Africa, mainly three groups are responsible for the compilation of dictionaries: (a) the National Lexicographic Units (NLUs), one for each official language, established by PanSALB, (b) the National Language Service (NLS) of the Department of Arts and Culture, and (c) commercial publishing houses and private individuals undertaking the production of general and technical dictionaries or word lists. General dictionaries, bilingual and monolingual, are compiled by the NLUs, whereas technical dictionaries and word lists are among the responsibilities of the NLS. Although all eleven official languages have at least some bilingual dictionaries, a developed dictionary culture has not yet been established for nine of the eleven languages.

There are two interdependent options to bring about a dictionary culture: (a) improve the skills of the dictionary users, and (b) improve the dictionaries themselves (Atkins and Varantola 1998: 83). Therefore, teaching the efficient use of dictionaries and compiling user-friendly dictionaries are the two most important challenges for lexicographers in South Africa. This article deals with the development of user skills, as "the majority of South Africans find themselves in a pre-dictionary culture environment" (Gouws and Prinsloo 2005: 42).

An officially multilingual country needs a dictionary culture, which includes at least all official languages of the country, i.e. eleven languages in the case of South Africa. Such a dictionary culture must be an inclusive model, based for example on the model of additive multilingualism or combined multiculturalism. This means that all user groups must be taken into account, because the South African dictionary users are not a homogeneous group. The different user groups include for example the general public, primary school pupils, secondary school pupils, teachers, and university students. Another feature which distinguishes the different groups is the existence of conjunctively written languages, i.e. the Nguni group (isiZulu, isiXhosa, Siswati and isiNdebele) and disjunctively written languages, i.e. the Sotho group (Sepedi, Sesotho, Setswana), Tshivenda and Xitsonga. 


\section{Implementing a dictionary culture in three steps}

The development of a dictionary culture can roughly be divided into three phases: (a) informing people that dictionaries are available, (b) teaching people how to use dictionaries efficiently, and (c) accepting that the use of dictionaries is something normal, i.e. an everyday activity children learn in school as well as at home.

\subsection{The information phase - Dictionary awareness campaigns}

Informing members of a speech community about available dictionaries and their benefits is the first step towards establishing a new dictionary culture. Dictionary awareness campaigns form an essential part in this information phase and should consist of three stages: (a) Showing people which dictionaries are available, i.e. going to the speech communities, introducing them to the actual products and telling them where these can be found. (b) Illustrating the benefits of dictionaries for their users. (c) Explaining to people how to use a dictionary.

Showing people the actual dictionaries is important, as it can help to eliminate the fear of contact with such strange books if people can handle them and browse through them. Another advantage is that it can be explained to people how to use a dictionary and let them try it themselves afterwards. Explaining to people the way to consult a dictionary could be done in two steps: (a) Demonstrating to them how they can find the word they are looking for. (b) Explaining to them how to decode the information the dictionary entry contains, i.e. finding information about the meaning, usage, pronunciation, spelling, and grammatical behaviour of a word.

Illustrating the benefits of dictionaries aims to help people realize that dictionaries are a valuable means of empowering them in everyday life, enabling them to communicate with other people on a broad range of topics, i.e. providing them with the words they need to talk or write about topics in new domains. There are three areas of communication-oriented functions in which dictionaries help their users: (a) text production, (b) text reception, and (c) translation of texts (Gouws and Prinsloo 2005: 14). In other words, they help to extend the knowledge of the mother tongue and assist users in learning foreign languages.

Another indirect advantage dictionaries have for their users is their symbolic value, i.e., they show that the language is worth to be written down, and that it can be used in practically all domains of life. This has the positive sideeffect that the status of the African languages is enhanced and that the L1 speakers of the African languages can be proud of their languages.

As the dictionary user is the most important factor deciding the success of a dictionary, a dictionary awareness campaign should be embarked on in accordance with the intended users. Questions to bear in mind concerning the users are: Who are the users? What do they know about the language? What do 
they know about dictionaries? Do they know how to use dictionaries? It is essential that the language of such campaigns is a language the people understand. This implies that they should be conducted in the relevant African language, i.e. the African language of the dictionary, and not only in English, for only $25 \%$ of all South Africans understand English.

In the South African context, dictionary awareness campaigns could be designed and carried out by the dictionary compilers with the help and support of the relevant NLUs. Although this will be a difficult task for the NLUs, which do not have such large staffs and as much money as commercial publishers, it is currently the only possibility to promote their dictionaries. Another advantage is that the compilers are not only mother-tongue speakers, but also lexicographers. In order to minimize the cost of such campaigns, several NLUs could co-operate and share the costs of developing a marketing strategy which could be adapted to their particular languages, i.e. one concept for all, but adjusted according to the different languages.

The media could also play an important part in these campaigns in order to reach as many people as possible. A successful example of a broad media coverage of the launch of a new dictionary was that of the release of the SeDiPro (Sesotho sa Leboa Dictionary Project) online dictionary in South African newspapers during July 2003, which resulted in a significantly higher use of the dictionary than the official academic launch two weeks earlier (De Schryver and Joffe 2004: 190). This can only be successful if the media such as newspapers and radio stations are informed of available dictionaries by giving facts about the dictionaries through to book editors and programme managers and presenting them with review copies. This also means that the dictionary compilers themselves should reach out to the speech communities telling them of the completed dictionary, giving them some useful information about it (such as the intended user group, benefits for the user, and value for the speech community and the language), and showing them the product and, if possible, presenting them with a free copy.

Another psychological factor is the co-operation with influential South African institutions and people, who could support a dictionary awareness campaign for their L1 speakers. Ordinary people must be able to identify with such institutions and people, because they are respected and admired in a specific community. Except for churches and schools and their office-bearers, musicians, TV stars and sportsmen can be employed on a voluntary basis for introducing dictionaries to the general public.

In short, a dictionary awareness campaign ideally consists of three main parts: (a) telling people what is available and showing them the actual products, (b) illustrating to them the benefits of dictionary use, and (c) explaining to them how to use dictionaries efficiently.

\section{$2.2 \quad$ Teaching dictionary use}

The teaching phase faces three major obstacles: (a) Different groups are to be 
taught, firstly, for example, dictionary compilers, lexicographic students, teachers, learners and students ranging from primary school to university, and, secondly, literate people who do not fit into any of these categories, but who also need training in consulting a dictionary. (b) At the moment, there are only a few skilled people who could do the teaching. (c) At first, all groups have to be taught simultaneously, which could lead to problems as the teachers especially must learn and at the same time teach what they are learning.

\subsubsection{Instructing dictionary compilers and lexicographic students}

Although there were some dictionaries compiled before the NLUs were established, the nine official African languages do not have a long dictionary tradition from which they could profit.

Examples of teaching lexicographic theory are workshops at certain lexicographic conferences and short courses at particular lexicographic units. At the Eleventh International Conference of AFRILEX a pre-conference workshop on "Principles and Practice of South African Lexicography" was presented. The Bureau of the WAT offers "a ten-day training course in general and computer lexicography and in the planning and management of a lexicographic project" (WAT 2005 online). In addition, the Department of Afrikaans and Dutch at the University of Stellenbosch have two postgraduate programmes on lexicography, an M.Phil. and a D.Litt. (SUN 2005 online). Such courses are valuable as they provide the first generation of properly trained lexicographers who are mother-tongue speakers of African languages.

\subsubsection{Teaching teachers}

Teachers, especially language teachers, but also subject teachers, should be able to use dictionaries confidently and knowledgeably and teach their pupils to consult dictionaries efficiently. Although a basic acquaintance with the theory of lexicography is useful for teachers, a confident use of dictionaries and a profound knowledge about dictionaries are more important. Because knowledge about dictionaries is a prerequisite for using dictionaries with confidence, it must therefore be taught to teachers. Such courses should be compulsory during teacher training and for all language teachers already in practice. They should include information on: (a) the benefits of dictionaries for the individual speaker, (b) the different dictionary types, (c) the contents of a dictionary, (d) the procedures to extract information from the dictionary, and (e) the methods to apply this information.

Being able to distinguish between the different dictionary types is important as they provide different kinds of information. Choosing the right type of dictionary is therefore vital for finding the desired information.

Knowledge about the contents of a dictionary concerns the structure of a dictionary, i.e. the difference between the central word list (what lay people call 
"the dictionary") and the front and back matter, which provide information about the dictionary.

The next step is to extract the correct information from the dictionary. This means that teachers must know the alphabetical structure of the dictionary to find the required lemma and the construction of the dictionary articles to decode the information in them. As this can be difficult, especially for conjunctively written languages, the lemmatization principle of the dictionary must be clear, i.e. it must be certain what counts as a lemma and in which cases derivational forms are listed as separate lemmas. Breaking the words down into their components in order to find the correct lemmatized stem is usually easier for L1 speakers with mother-tongue intuition than for learners who are unsure to which noun or verb category a word belongs. Electronic dictionaries avoid this problem by including all forms and guiding the user directly to the correct lemma. Finding a solution to this problem for paper versions of the dictionaries will be an important step towards successful dictionary use. A first step in solving this problem is that dictionary compilers should state which lemmatization approach was used and which cases were considered as exceptions, explaining these clearly in the usage guide in the front matter of the dictionary. This leads to the next important aspect, which must be included in such a course: the use of the front and back matter of the dictionary. As these contain important information about the structure and contents of the dictionary and, ideally, a usage guide, they should not be ignored but considered as vital a part as the central word list.

Another important aspect to be treated in training teachers is illustrating ways to introduce dictionary use in the classroom. This is of special importance for language teachers who could use dictionaries in activities such as text reception, text production or translation.

\subsubsection{Teaching pupils}

The aim of teaching effective dictionary use, i.e. finding with confidence the correct information in the dictionary, is the same for all groups. Nevertheless, different approaches are needed for the different languages, age groups, as well as for L1 speakers and language learners. Teaching dictionary use should start as early as possible to ensure that pupils internalize it in their formative years. Dictionary use should not be taught as a single module, i.e. a module learnt for an examination and forgotten afterwards, because this will not lead to a regular consultation of dictionaries. Instead, the dictionary should be introduced as a useful tool helping students to communicate. It should be integrated on a regular basis in text decoding (reading) as well as text production (writing, speaking and word games), because practising the use of dictionaries is the only way of coming into the routine of using them. Starting to teach dictionary use in primary school implies that there must be school dictionaries available which suit the age of the users. This means they must be easy to use and must be written in a language the pupils understand in order to help them 
to improve their communication skills (Gouws and Prinsloo 2005: 51). It is an important task for lexicographers to compile dictionaries for all age groups and especially for younger pupils, as they will be the ones who will be taught from primary school onwards how to use dictionaries. They could be members of the first generation of a new dictionary culture.

\subsubsection{Teaching everybody else who needs to consult a dictionary}

Teaching dictionary use is not only restricted to pupils, but must involve the whole speech community, i.e., everybody who may need to consult a dictionary. In speech communities where there is not an established dictionary culture yet, this will be very difficult as most of the speakers have already finished their formal education and cannot easily be reached. For these people, teaching dictionary use could mainly be done through dictionary awareness campaigns and the dictionaries themselves. This means that the front and back matter of dictionaries, and especially the user guides, are very important, because they will influence the success of the user. If the guide clearly explains how to find a word, i.e. if the lemmatization principle is clear and illustrative examples are given, users of the dictionary will, hopefully, find the meaning and use of the unknown word which they have come across.

\subsection{The consolidation phase - The next generation}

The last phase in establishing a dictionary culture will be the consolidation phase in which the use of a dictionary will become a normal, everyday activity for most members of the speech community. Or, as Jackson (2002: 21) puts it, "the dictionary (will) become part of the cultural fabric of (the) society". In this phase, the speech community takes over so that a dictionary culture will develop and grow through a system of cumulative distribution. Those pupils who will learn the consultation of a dictionary from an early age (ideally from primary level) onwards, will be the foundation on which this consolidation phase is built as they will have cultivated the use of a dictionary, teaching it to their children as a useful and informative procedure.

During this phase, there is a switch from a top-down to a bottom-up approach, i.e. the NLUs would not be able to control and direct the scene completely as the speech community will have more influence.

This phase includes not only a regular use of dictionaries in education, but also a feedback on the dictionaries by their users. This means that the speech community must be able to contact the lexicographers, giving them their opinions and experiences. Examples would be the feedback forms of online dictionaries (cf. SeDiPro) or any written or oral communication between the lexicographers and the users. A successful dictionary culture can only be established if the members of the speech community accept the dictionaries as something useful and informative in their own lives. 


\section{Conclusion}

A successful dictionary culture needs an ongoing co-operation between lexicographers, who are compiling the dictionaries, on the one hand, and teachers, who are a vital factor in developing a dictionary culture, on the other. For South Africa, an inclusive dictionary culture is called for, i.e. a multilingual one comprising all official languages. This means that the theoretical concept is the same for all languages, but the actual models must be modified according to the needs of each speech community and each language. This aim could be reached through a strategy in which two approaches are applied simultaneously. The first is a broad short-term measure (the formation phase) that tries to reach as many people as possible and familiarize them with dictionaries through dictionary awareness campaigns. The second is a long-term measure (the teaching phase) that would not reach as many people as the dictionary awareness campaigns in the first years, but will produce a generation who has internalized dictionary use, seeing it as a normal, everyday activity.

\section{Acknowledgement}

I am grateful to Dr F. Rautert and Prof. E. Wolff for a very helpful and constructive critique of an earlier version of this article. However, they obviously carry no responsibility for any part of it.

\section{Literature}

\section{Dictionaries}

SeDiPro. http://africanlanguages.com/sdp/.

\section{Other literature}

Atkins, S. and K. Varantola. 1998. Monitoring Dictionary Use. Atkins, S. (Ed.). 1998. Using Dictionaries: 21-82. Tübingen: Max Niemeyer.

De Schryver, G.-M. and D. Joffe. 2004. On How Electronic Dictionaries Are Really Used. http:// www.tshwanedje.com.

Gouws, R. and D. Prinsloo. 2005. Principles and Practice of South African Lexicography. Stellenbosch: SUN PReSS.

Jackson, H. 2002. Lexicography: An Introduction. London: Routledge.

SUN (2005 online) http://academic.sun.ac.za/afrndl/programme/index.htm.

WAT (2005 online) http://www.sun.ac.za/wat/Engelse\%20Webwerf/Training/WFB2.HTM. 